\title{
Tolerância da maçã 'Fuji’ a baixas temperaturas durante o armazenamento em atmosfera controlada
}

\section{Tolerance of 'Fuji' apple at low temperatures during storage in controlled atmosphere}

\author{
Auri Brackmann ${ }^{1}$; Marcelo Ceretta ${ }^{2}$; Alessandro Dal'Col Lúcio ${ }^{3}$; Josuel Alfredo \\ Vilela Pinto ${ }^{4}$; Rogério Oliveira Anese ${ }^{5 *}$
}

\section{Resumo}

O objetivo deste trabalho foi avaliar a tolerância da maçã cultivar 'Fuji' a baixas temperaturas durante os diferentes períodos, no início ou no final do armazenamento, bem como o seu efeito na qualidade do fruto. Os tratamentos constituíram-se de temperaturas $\left(-0,5^{\circ} \mathrm{C},-0,8^{\circ} \mathrm{C}\right.$ e $\left.-1,6^{\circ} \mathrm{C}\right)$, durante oito meses de armazenamento ininterruptos em atmosfera controlada $\left(\mathrm{AC}-1,0 \mathrm{kPa}\right.$ de $\mathrm{O}_{2}+<0,5 \mathrm{kPa}$ de $\mathrm{CO}_{2}$ ), e da combinação destas temperaturas em diferentes períodos de tempo no início ou no final do armazenamento. As análises de qualidade foram realizadas após oito meses de armazenamento mais sete dias de exposição à temperatura de $20^{\circ} \mathrm{C}$. Para maçãs cultivar Fuji, temperaturas de $-0,8^{\circ} \mathrm{C}$, ou inferior, quando usadas no início do armazenamento, provocam maior degenerescência causada por baixa temperatura e tendem a causar mais podridões. No entanto, a temperatura de $-0,8^{\circ} \mathrm{C}$ pode ser usada no final do armazenamento, assim mantendo melhor a qualidade da maçã 'Fuji' durante o armazenamento em atmosfera controlada.

Palavras-chave: Malus domestica, pós-colheita, conservação, temperatura

\begin{abstract}
The aim of this research was to evaluate the tolerance of 'Fuji' apple at low temperatures during the different periods at the beginning or end of storage as well as its effect on fruit quality. The treatments consisted of temperatures $\left(-0.5^{\circ} \mathrm{C},-0.8^{\circ} \mathrm{C}\right.$ and $\left.-1.6^{\circ} \mathrm{C}\right)$ for eight months of continuous storage in controlled atmosphere $\left(\mathrm{CA}-1,0 \mathrm{kPa}\right.$ of $\mathrm{O}_{2}+<0,5 \mathrm{kPa}$ of $\mathrm{CO}_{2}$ ), and their combination at different temperatures periods of time at the beginning or end of storage. The quality analysis was done after eight months of storage plus seven days at a temperature of $20^{\circ} \mathrm{C}$. For 'Fuji' apple, temperatures of $-0.8^{\circ} \mathrm{C}$ or lower, when used at the beginning of storage, caused more internal breakdown caused by the cold and tend to cause more decay. However, the temperature of $-0.8^{\circ} \mathrm{C}$ can be used at the end of storage, thus maintaining the best quality of apples during controlled atmosphere storage.
\end{abstract}

Key words: Malus domestica, postharvest, conservation, temperature

\footnotetext{
1 Eng $^{\mathrm{o}} \mathrm{Agr}^{\mathrm{o}}$ Prof. Dr. do Dept ${ }^{\mathrm{o}}$ de Fitotecnia Universidade Federal de Santa Maria, UFSM, Centro de Ciências Rurais, Av. Roraima, no 1000, Cidade Universitária, Bairro Camobi, CEP 97105-900 Santa Maria, RS. E-mail: auribrackmann@gmail.com

2 Fiscal agropecuário, Ministério da Agricultura, Pecuária e Abastecimento, MAPA. Unidade de Santa Maria. E-mail: marcelo. ceretta@agricultura.gov.br

3 Eng $^{\circ}$ Agr $^{\circ}$, Prof. Dr. do Dept ${ }^{\circ}$ de Fitotecnia Universidade Federal de Santa Maria, UFSM. E-mail: adlucio.capi@gmail.com

4 Eng ${ }^{\mathrm{o}}$ Agr $^{\circ}$, Prof. Assistente da Universidade Federal da Fronteira Sul, Campus de Laranjeiras do Sul, PR. E-mail: josuelpinto@ bol.com.br

5 Acadêmico do curso de Agronomia da Universidade Federal de Santa Maria, UFSM. Bolsista Pibic/CNPq. E-mail: rogerio_ anese@yahoo.com.br

* Autor para correspondência
} 
A colheita da maçã 'Fuji' é realizada, nas condições climáticas brasileiras, nos meses de março e abril. Para a regulação da oferta de frutos ao mercado durante o ano, faz-se necessário o uso do armazenamento em atmosfera controlada (AC), o qual consiste no controle dos níveis de oxigênio $\left(\mathrm{O}_{2}\right)$ e gás carbônico $\left(\mathrm{CO}_{2}\right)$ na câmara de armazenagem, além do controle da temperatura e umidade relativa do ar. O controle da temperatura é o fator primordial para a conservação pós-colheita de frutos, sendo que, quando controlada inadequadamente, pode causar grandes perdas devido ao congelamento ou às desordens, como degenerescência por baixa temperatura (CHITARRA; CHITARRA, 2005).

A temperatura controla a velocidade com que ocorrem as reações bioquímicas na célula, dentre elas, a respiração e a produção de etileno (ASIF et al., 2009), que estão inteiramente correlacionadas com a conservação da qualidade de maçãs armazenadas. Para o armazenamento de maçãs 'Fuji', as empresas utilizam na câmara de armazenamento a temperatura de $-0,5^{\circ} \mathrm{C}$, visto que Brackmann et al. (2009) e Brackmann, Bortoluz e Bortoluzzi (1998) encontraram melhor manutenção da qualidade a $-0,5^{\circ} \mathrm{C}$ comparado $0,5^{\circ} \mathrm{C}$. Tendo em vista que a redução da temperatura de 0,5 para $-0,5^{\circ} \mathrm{C}$ proporcionou melhor qualidade da maçã 'Fuji', existe a possibilidade da utilização de temperaturas inferiores a esta, em determinadas fases do período de conservação, já que o estresse por baixa temperatura parece ser maior no início do armazenamento (LITTLE; BARRAND, 1989; FLORES-CANTILLANO; GIRARDI, 2004), o que ajudaria suprimir ainda mais o metabolismo do fruto, contribuindo para uma maior manutenção da qualidade dos frutos e redução das perdas em pós-colheita.

Na utilização de baixas temperaturas poderá ocorrer congelamentodolíquidocelulardo fruto, principalmente o do vacúolo, havendo formação de cristais dentro da célula. Com isso rompem-se as membranas da célula, e ao descongelar, há extravasamento de líquidos, que na presença de $\mathrm{O}_{2}$ e enzimas citoplasmáticas ocorre oxidação de compostos químicos, como fenóis que causam escurecimento dos tecidos (LYONS, 1973), caracterizado como degenerescência. $\mathrm{O}$ dano por congelamento inicia seu desenvolvimento na parte mediana da polpa, frequentemente se estendendo numa faixa contínua. As áreas afetadas apresentam uma coloração marrom-clara e é separada da epiderme por uma camada de tecido sadio, característica que permite distinguir esse distúrbio da degenerescência interna causada pela senescência. Frequentemente não aparecem sintomas externos, porém o fruto parece ser levemente esponjoso ao ser comprimido, e ao contrário da degenerescência senescente, o dano não progride quando o fruto é exposto à temperatura ambiente (GRAN; BEAUDRY, 1993).

Apesar de se ter o conhecimento que a maçã cultivar Fuji mantém melhor sua qualidade na temperatura de $-0,5^{\circ} \mathrm{C}$ do que em temperaturas superiores, ainda não se tem informações sobre o uso de temperaturas menores do que esta na conservação da qualidade desta maçã. Diante disto, o objetivo deste trabalho foi avaliar a possibilidade do uso de temperaturas inferiores a $0,5^{\circ} \mathrm{C}$ durante os diferentes períodos, no início ou no final do armazenamento, bem como o seu efeito na qualidade físico-química da maçã cultivar Fuji.

Os frutos da cultivar Fuji, utilizados no experimento, foram provenientes de um pomar comercial localizado no município de Vacaria, RS, Brasil. Antes do armazenamento foi realizada a seleção dos frutos e homogeneização das amostras experimentais, sendo eliminados os frutos com lesões e com baixo calibre. Os frutos apresentavam antes da instalação do experimento: firmeza da polpa de $71,8 \mathrm{~N}$; acidez de $3,46 \mathrm{cmol}^{-\mathrm{L}^{-1}}$; SS de $13,0^{\circ}$ Brix e índice iodo-amido (110) de $6,7$.

Arelação dos tratamentos está apresentada na tabela 1. As temperaturas usadas foram $-0,5^{\circ} \mathrm{C}$ (padrão), $-0,8^{\circ} \mathrm{C} \mathrm{e}-1,6^{\circ} \mathrm{C}$, as quais foram utilizadas durante o período inicial ou período final do armazenamento, conforme pode ser observado na Tabela 1, ou então durante todo o período de armazenamento, sempre completando um tempo total de oito meses. A pressão parcial de gases usada no experimento foi de $1,0 \mathrm{kPa}$ de $\mathrm{O}_{2}+<0,5 \mathrm{kPa}$ de $\mathrm{CO}_{2}$. A pressão parcial inicial de $\mathrm{O}_{2}$ 
foi obtida pelo princípio de diluição com a varredura do $\mathrm{O}_{2}$ através da injeção do gás nitrogênio, proveniente de um gerador que utiliza o sistema "Pressure Swing Adsorption" (PSA), até a obtenção da pressão parcial pré-estabelecida. A pressão parcial de $\mathrm{CO}_{2}$ foi obtida através da injeção deste gás, proveniente de um cilindro de alta pressão. Para a manutenção dos níveis de $\mathrm{O}_{2}$ e $\mathrm{CO}_{2}$, que se modificavam em função da respiração dos frutos, foram realizadas diariamente análises e correções das pressões parciais dos gases, com o auxílio do sistema automático de controle de gases da marca Kronenberger. Assim, para repor o $\mathrm{O}_{2}$ consumido na respiração dos frutos, injetou-se ar atmosférico nas minicâmaras e o $\mathrm{CO}_{2}$, produzido pela respiração, foi absorvido por uma solução de hidróxido de potássio (40\%), pela qual circulava o ar das minicâmaras.

Tabela 1. Relação dos tratamentos com baixas temperaturas para a maçã 'Fuji' em atmosfera controlada (AC) de $1,0 \mathrm{kPa} \mathrm{O}_{2}+<0,5 \mathrm{kPa} \mathrm{CO}_{2}$ e definição dos contrastes com respectivos coeficientes.

\begin{tabular}{|c|c|c|c|}
\hline \multirow{2}{*}{$\begin{array}{l}\text { Temperatura } \\
\text { e tempo de exposição }\end{array}$} & \multicolumn{3}{|c|}{ Contrastes e Coeficientes } \\
\hline & $\begin{array}{c}\mathrm{X} 1= \\
\text { Comparação } \\
\text { de }-0,5^{\circ} \mathrm{C} \text { com }-0,8^{\circ} \mathrm{C} \\
\mathrm{e}-1,6^{\circ} \mathrm{C} \\
\end{array}$ & $\begin{array}{c}\mathrm{X} 2= \\
\text { Comparação de }-0,8^{\circ} \mathrm{C} \\
\text { no início, com }-0,8^{\circ} \mathrm{C} \text { no } \\
\text { final do armazenamento }\end{array}$ & $\begin{array}{c}\mathrm{X3}= \\
\text { Comparação de }-1,6^{\circ} \mathrm{C} \text { no } \\
\text { início, com }-1,6^{\circ} \mathrm{C} \text { no } \\
\text { final do armazenamento }\end{array}$ \\
\hline$-0,5^{\circ} \mathrm{C}$ por 8 meses (padrão) & 2 & 0 & 0 \\
\hline$-0,8^{\circ} \mathrm{C}$ por 8 meses & -1 & 0 & 0 \\
\hline $\begin{array}{l}-1,6^{\circ} \mathrm{C} \text { por } 8 \text { meses } \\
-0,8 \mathrm{C}^{\circ} \text { por } 2 \text { meses }^{1}+\end{array}$ & -1 & 0 & 0 \\
\hline $\begin{array}{l}\left(-0,5^{\circ} \mathrm{C}\right) \text { por } 6 \text { meses }^{2} \\
-0,8^{\circ} \mathrm{C} \text { por } 4 \text { meses }+\end{array}$ & 0 & 1 & 0 \\
\hline $\begin{array}{l}\left(-0,5^{\circ} \mathrm{C}\right) \text { por } 4 \text { meses } \\
-0,5^{\circ} \mathrm{C} \text { por } 6 \text { meses }+\end{array}$ & 0 & 1 & 0 \\
\hline $\begin{array}{l}\left(-0,8^{\circ} \mathrm{C}\right) \text { por } 2 \text { meses } \\
-0,5^{\circ} \mathrm{C} \text { por } 4 \text { meses }+\end{array}$ & 0 & -1 & 0 \\
\hline $\begin{array}{l}\left(-0,8^{\circ} \mathrm{C}\right) \text { por } 4 \text { meses } \\
-1,6^{\circ} \mathrm{C} \text { por } 1 / 2 \text { mês }+\end{array}$ & 0 & -1 & 0 \\
\hline $\begin{array}{l}\left(-0,5^{\circ} \mathrm{C}\right) \text { por } 7 \frac{1}{2} \text { meses } \\
-1,6^{\circ} \mathrm{C} \text { por } 1 \text { mês }+\end{array}$ & 0 & 0 & 1 \\
\hline $\begin{array}{l}\left(-0,5^{\circ} \mathrm{C}\right) \text { por } 7 \text { meses } \\
-1,6^{\circ} \mathrm{C} \text { por } 2 \text { meses }+\end{array}$ & 0 & 0 & 1 \\
\hline $\begin{array}{l}\left(-0,5^{\circ} \mathrm{C}\right) \text { por } 6 \text { meses } \\
-1,6^{\circ} \mathrm{C} \text { por } 4 \text { meses }+\end{array}$ & 0 & 0 & 1 \\
\hline $\begin{array}{l}\left(-0,5^{\circ} \mathrm{C}\right) \text { por } 4 \text { meses } \\
-0,5^{\circ} \mathrm{C} \text { por } 71 / 2 \text { meses }+\end{array}$ & 0 & 0 & 1 \\
\hline $\begin{array}{l}\left(-1,6^{\circ} \mathrm{C}\right) \text { por } 1 / 2 \text { mês } \\
-0,5^{\circ} \mathrm{C} \text { por } 7 \text { meses }+\end{array}$ & 0 & 0 & -1 \\
\hline $\begin{array}{l}\left(-1,6^{\circ} \mathrm{C}\right) \text { por } 1 \text { mês } \\
-0,5^{\circ} \mathrm{C} \text { por } 6 \text { meses }+\end{array}$ & 0 & 0 & -1 \\
\hline$\left(-1,6^{\circ} \mathrm{C}\right)$ por 2 meses & 0 & 0 & -1 \\
\hline $\begin{array}{l}-0,5^{\circ} \mathrm{C} \text { por } 4 \text { meses }+ \\
\left(-1,6^{\circ} \mathrm{C}\right) \text { por } 4 \text { meses }\end{array}$ & 0 & 0 & -1 \\
\hline
\end{tabular}

${ }^{1}$ No início do armazenamento. ${ }^{2}$ No final do armazenamento. 
A temperatura de armazenamento foi regulada por um termostato de alta precisão, sendo monitorada durante todo o período de armazenamento por termômetros com bulbo de mercúrio introduzidos na polpa de frutos, havendo uma oscilação de $\pm 0,1^{\circ} \mathrm{C}$.

O delineamento experimental adotado foi o inteiramente casualizado, com quatro repetições e a unidade experimental composta de 20 frutos. Foi efetuado análise da variância, teste "F" e contraste, método de Scheffé, em que a comparação deu-se entre grupos de tratamentos e não entre todos os tratamentos. As variáveis expressas em porcentagem foram transformadas pela fórmula arc.sen $\sqrt{\mathrm{x} / 100}$ antes da análise da variância. Foram efetuadas somente dois tipos de estimativas de contrastes, a saber:

a) Entre o tratamento considerado padrão, versus tratamentos com temperaturas mais baixas, armazenados por oito meses ininterruptamente (contrastes $\mathrm{X}_{1}$, Tabela 1);

b) Comparação entre grupos de tratamentos com temperaturas mais baixas no período inicial do armazenamento, versus os grupos de tratamentos que tinham estas mesmas temperaturas, porém no período final (contrastes $\mathrm{X}_{2}$ e $\mathrm{X}_{3}$ ).

Após o período de armazenamento, os frutos foram mantidos por sete dias em uma câmara na temperatura de $20^{\circ} \mathrm{C}$ para simular o período de comercialização, sendo posteriormente avaliados os seguintes parâmetros: firmeza da polpa, foi determinada por meio de penetrômetro com ponteira de $11 \mathrm{~mm}$, aplicado em dois lados da região equatorial do fruto, onde foi retirada previamente a epiderme e foi expressa em Newton $(\mathrm{N})$; acidez titulável, foram utilizados $10 \mathrm{~mL}$ de suco que foram diluídos em $100 \mathrm{~mL}$ de água destilada e titulados com hidróxido de sódio a $0,1 \mathrm{~N}$ até $\mathrm{pH} 8,1$ sendo expressa em meq $100 \mathrm{ml}^{-}$ 1; sólidos solúveis, obtido por refratometria e expresso em ${ }^{\circ}$ Brix; degenerescência por baixa temperatura, avaliada após a realização de vários cortes na secção transversal dos frutos, o que permitiu a contagem de frutos que apresentavamse com aspecto mole, coloração marrom, inclusive no miolo dos frutos, sendo os resultados expressos em porcentagem; degenerescência corticenta, obtida pela contagem dos frutos que apresentavam pequenas lesões de aspecto corticento e seco, às vezes, com pequenas cavernas; podridões, foram determinadas pela contagem de frutos que apresentavam lesões causadas por fungos patogênicos, sendo que os valores foram expressos em porcentagem; e produção de etileno, obtida através de cromatografia gasosa (cromatógrafo $\operatorname{Varian}^{\circledR}$, modelo CX3400), sendo os resultados expressos em $\mu \mathrm{L}$ de $\mathrm{C}_{2} \mathrm{H}_{4} \mathrm{~kg}^{-1} \mathrm{~h}^{-1}$.

As estimativas de contrastes para as variáveis firmeza de polpa, acidez titulável, SS mostram um efeito não significativo (Tabela 2).

As estimativas de contraste $X_{1}$ para degenerescência por baixa temperatura mostraram efeito significativo entre o tratamento considerado padrão, $-0,5^{\circ} \mathrm{C}$, em relação aos tratamentos com armazenamento a $-0,8^{\circ} \mathrm{C}$ e $-1,6^{\circ} \mathrm{C}$ (Tabelas 2). No tratamento padrão não houve degenerescência por baixa temperatura. Já na temperatura de $-0,8^{\circ} \mathrm{C}$, o dano foi menor comparado a $-1,6^{\circ} \mathrm{C}$.(Tabela 2 ). Provavelmente, a temperatura de $-1,6^{\circ} \mathrm{C}$ provocou maior dano na célula, o que causou extravasamento de líquidos, que na presença de $\mathrm{O}_{2}$ e enzimas citoplasmáticas ocorreu oxidação de compostos químicos, como fenóis que causaram escurecimento dos tecidos, caracterizado como degenerescência (LYONS, 1973). 
Tabela 2. Média das variáveis que indicam a qualidade da maçã 'Fuji' armazenada em diferentes temperaturas e diferentes períodos de exposição, após 8 meses em atmosfera controlada (AC) $\left(1,0 \mathrm{kPa} \mathrm{O}_{2}+\right.$ $<0,5 \mathrm{kPa} \mathrm{CO}$ ), mais 7 dias a $20{ }^{\circ} \mathrm{C}$ e estimativas de contrastes para as variáveis.

\begin{tabular}{|c|c|c|c|c|c|c|c|c|}
\hline $\begin{array}{l}\text { Temperatura e } \\
\text { tempo de exposição }\end{array}$ & $\begin{array}{l}\text { Firmeza } \\
\text { de polpa } \\
(\mathrm{N})\end{array}$ & $\begin{array}{c}\text { Acidez } \\
\left(\text { cmol.L }^{-1}\right)\end{array}$ & $\begin{array}{c}\text { SS } \\
\text { (Brix) }\end{array}$ & $\begin{array}{c}\text { Deg. por baixa } \\
\text { temperatura } \\
(\%)\end{array}$ & $\begin{array}{c}\text { Deg. } \\
\text { corticenta } \\
(\%)\end{array}$ & $\begin{array}{l}\text { Podridã } \\
0 \text { dia }\end{array}$ & $\begin{array}{l}\text { io }(\%) \\
7 \text { dias }\end{array}$ & $\begin{array}{r}{ }^{1} \mathrm{C}_{2} \mathrm{H}_{4} \\
\left(\mu \mathbf{L k g}^{-1}\right. \\
\left.\mathbf{h}^{-1}\right)\end{array}$ \\
\hline$-0,5^{\circ} \mathrm{C}$ por 8 meses & 70,3 & 3,42 & 14,0 & 0,00 & 0,00 & 5,0 & 9,5 & $\overline{1,47}$ \\
\hline$-0,8^{\circ} \mathrm{C}$ por 8 meses & 70,1 & 3,12 & 14,0 & 1,25 & 0,00 & 12,5 & 26,5 & 0,49 \\
\hline $\begin{array}{l}-1,6^{\circ} \mathrm{C} \text { por } 8 \text { meses } \\
-0,8 \mathrm{C}^{\circ} \text { por } 2 \text { meses }+\end{array}$ & 74,2 & 2,44 & 13,8 & 18,50 & 0,00 & 16,3 & 70,0 & 0,50 \\
\hline $\begin{array}{l}\left(-0,5^{\circ} \mathrm{C}\right) \text { por } 6 \text { meses } \\
-0,8^{\circ} \mathrm{C} \text { por } 4 \text { meses }+\end{array}$ & 68,8 & 3,33 & 13,9 & 2,56 & 0,00 & 6,2 & 17,0 & 1,22 \\
\hline $\begin{array}{l}\left(-0,5^{\circ} \mathrm{C}\right) \text { por } 4 \text { meses } \\
-0,5^{\circ} \mathrm{C} \text { por } 6 \text { meses }+\end{array}$ & 68,6 & 3,01 & 14,1 & 1,25 & 0,00 & 1,2 & 18,9 & 0,97 \\
\hline $\begin{array}{l}\left(-0,8^{\circ} \mathrm{C}\right) \text { por } 2 \text { meses } \\
-0,5^{\circ} \mathrm{C} \text { por } 4 \text { meses }+\end{array}$ & 76,5 & 2,81 & 13,9 & 0,00 & 0,00 & 0,0 & 4,41 & 1,09 \\
\hline $\begin{array}{l}\left(-0,8^{\circ} \mathrm{C}\right) \text { por } 4 \text { meses } \\
-1,6^{\circ} \mathrm{C} \text { por } 1 / 2 \text { mês }+\end{array}$ & 78,7 & 2,68 & 13,9 & 2,50 & 0,00 & 2,5 & 6,31 & 1,29 \\
\hline $\begin{array}{l}\left(-0,5^{\circ} \mathrm{C}\right) \text { por } 71 / 2 \text { meses } \\
-1,6^{\circ} \mathrm{C} \text { por } 1 \text { mês }+\end{array}$ & 78,0 & 2,47 & 13,9 & 0,00 & 1,25 & 6,2 & 12,2 & 1,04 \\
\hline $\begin{array}{l}\left(-0,5^{\circ} \mathrm{C}\right) \text { por } 7 \text { meses } \\
-1,6^{\circ} \mathrm{C} \text { por } 2 \text { meses }+\end{array}$ & 76,6 & 2,45 & 13,8 & 0,00 & 2,77 & 11,2 & 33,3 & 0,83 \\
\hline $\begin{array}{l}\left(-0,5^{\circ} \mathrm{C}\right) \text { por } 6 \text { meses } \\
-1,6^{\circ} \mathrm{C} \text { por } 4 \text { meses }+\end{array}$ & 76,4 & 2,44 & 13,9 & 2,63 & 1,31 & 11,3 & 29,7 & 0,83 \\
\hline $\begin{array}{l}\left(-0,5^{\circ} \mathrm{C}\right) \text { por } 4 \text { meses } \\
-0,5^{\circ} \mathrm{C} \text { por } 71 / 2 \text { meses }+\end{array}$ & 74,7 & 2,46 & 13,9 & 14,45 & 1,56 & 22,5 & 55,6 & 0,68 \\
\hline $\begin{array}{l}\left(-1,6^{\circ} \mathrm{C}\right) \text { por } 1 / 2 \text { mês } \\
-0,5^{\circ} \mathrm{C} \text { por } 7 \text { meses }+\end{array}$ & 74,8 & 2,74 & 13,8 & 0,00 & 0,00 & 10,0 & 22,0 & 1,86 \\
\hline $\begin{array}{l}\left(-1,6^{\circ} \mathrm{C}\right) \text { por } 1 \text { mês } \\
-0,5^{\circ} \mathrm{C} \text { por } 6 \text { meses }+\end{array}$ & 74,7 & 2,60 & 14,0 & 3,75 & 1,47 & 10,0 & 22,0 & 1,25 \\
\hline $\begin{array}{l}\left(-1,6^{\circ} \mathrm{C}\right) \text { por } 2 \text { meses } \\
-0,5^{\circ} \mathrm{C} \text { por } 4 \text { meses }+\end{array}$ & 79,4 & 2,45 & 14,1 & 2,56 & 0,00 & 11,3 & 17,3 & 1,17 \\
\hline$\left(-1,6^{\circ} \mathrm{C}\right)$ por 4 meses & 75,6 & 2,23 & 13,6 & 8,57 & 0,00 & 16,2 & 54,7 & 0,64 \\
\hline \multicolumn{9}{|c|}{ Estimativas dos contrastes } \\
\hline $\mathrm{X} 1$ & $-0,38^{\mathrm{ns}}$ & 1,28 ns & $0,27^{\mathrm{ns}}$ & $-19,75^{*}$ & $0,00^{\mathrm{ns}}$ & $-18,8^{*}$ & $-7,74$ & $1,95^{*}$ \\
\hline $\mathrm{X} 2$ & $-1,82$ ns & $0,85^{\mathrm{ns}}$ & $0,20^{\mathrm{ns}}$ & $1,00 *$ & 0,00 ns & $5,00 *$ & $25,18^{*}$ & $-0,19$ ns \\
\hline $\mathrm{X} 3$ & $0,11^{\mathrm{ns}}$ & $-0,20^{\mathrm{ns}}$ & $0,10^{\mathrm{ns}}$ & $2,2 *$ & $5,42 \mathrm{~ns}$ & $3,75^{*}$ & $1,39 *$ & $-1,544^{\mathrm{ns}}$ \\
\hline
\end{tabular}

${ }^{(1)}=$ Médias de 2 dias, a $20^{\circ} \mathrm{C}$;

*: significativo pelo teste de Scheffé em nível de 5\% de probabilidade; ns : não significativo.

Nos contrastes $\mathrm{X}_{2}$ e $\mathrm{X}_{3}$, onde foram comparados os grupos de tratamentos com as temperaturas mais baixas no período inicial com os grupos de tratamentos que apresentaram essas mesmas 
temperaturas no período final do armazenamento, constatou-se maior incidência de degenerescência interna nos frutos submetidos a temperaturas mais baixas no período inicial do armazenamento (Tabela 2). A ocorrência de maior percentual de degenerescência por baixa temperatura nos frutos submetidos a temperaturas mais baixas no período inicial de armazenamento pode estar relacionado ao seu estádio de maturação, que no início do armazenamento ainda não é completo, sendo, portanto o fruto mais sensível nesta fase (LITTLE; BARRAND, 1989; WATKINS et al., 1997; FLORES-CANTILLANO; GIRARDI, 2004).

Com relação à degenerescência corticenta, os frutos que foram expostos à baixa temperatura no período inicial do armazenamento, nesse caso somente $-1,6^{\circ} \mathrm{C}$, apresentaram maior degenerescência corticenta, entretanto, sem apresentar efeito significativo. A degenerescência corticenta, frequentemente está mais relacionada ao alto $\mathrm{CO}_{2}$ na câmara de armazenagem (JAMES; JOBLING, 2009) do que ao estresse por baixa temperatura. Nesse experimento, porém como o $\mathrm{CO}_{2}$ usado nas câmaras estava baixo $(<0,5 \mathrm{kPa})$, o que é ideal para 'Fuji', o estresse inicial por frio pode ter tido influência na degenerescência corticenta. Volz et al. (1998) afirmam que a 'Fuji', produzida na Califórnia, é muito sensível ao $\mathrm{CO}_{2}$ usado durante sua conservação. No Brasil, também é uma cultivar que não tolera a presença desse gás na câmara. Diversos trabalhos demonstraram que o $\mathrm{CO}_{2}$, mesmo em baixas concentrações, pode ser prejudicial.Brackmann, BortoluzeBortoluzzi(1998) constataram 11,7\% de dano em 'Fuji' armazenada sob $0,5 \mathrm{kPa}$ de $\mathrm{CO}_{2}$. Porém, mais recentemente, Brackmann et al. (2001), trabalhando com apenas $0,2 \mathrm{kPa}$ de $\mathrm{CO}_{2}$, observaram $7 \%$ de degenerescência com cortiça, o que levanta a hipótese que esse dano nem sempre é produzido pelo $\mathrm{CO}_{2}$. Apesar desse distúrbio não ser frequente, quando o $\mathrm{CO}_{2}$ está abaixo do nível crítico, o estresse inicial por temperaturas muito baixas poderia provocar dano característico de $\mathrm{CO}_{2}$, ou seja degenerescência com cortiça e até cavernas na polpa.

Para a incidência de podridões, quando se compara o tratamento considerado padrão, com os tratamentos com temperaturas mais baixas, mantidos ininterruptamente por oito meses (contrastes $\mathrm{X}_{1}$ ), a incidência foi menor somente no tratamento padrão. Esses resultados foram constatados na avaliação efetuada logo após a abertura das câmaras e também após exposição dos frutos por sete dias a $20^{\circ} \mathrm{C}$. A temperatura de $-0,8$ e $-1,6^{\circ} \mathrm{C}$ durante oito meses, usadas de forma ininterruptas, agravaram a incidência de podridões. Nos contrastes $\mathrm{X}_{2}$ e $\mathrm{X}_{3}$, em que se compararam os grupos de tratamentos, constatou-se, maior incidência de podridão nos frutos submetidos a temperaturas mais baixas no início do armazenamento. Ficou evidente então, que temperaturas mais baixas no início, são mais prejudiciais do que no final do período de armazenamento. Quando essas mesmas temperaturas foram aplicadas por igual período, porém no final do armazenamento, a incidência de podridões foi menor, mesmo após a exposição dos frutos por sete dias a $20^{\circ} \mathrm{C}$. Brackmann, Steffens e Hunsche (2000), trabalhando com a maçã 'Fuji', constataram que temperatura mais elevada, $2,5^{\circ} \mathrm{C}$, por 40 dias no início do armazenamento, reduziu a ocorrência de podridões. Temperaturas muito baixas no início do armazenamento parece que causam um estresse nos frutos, que os torna mais vulneráveis ao ataque de patógenos causadores de podridões.

Para a variável produção de etileno, o contraste $\mathrm{X}_{1}$ (Tabela 2) entre o tratamento considerado padrão, $-0,5^{\circ} \mathrm{C}$ por oito meses, produziu mais etileno que os outros dois tratamentos com temperaturas de $-0,8^{\circ} \mathrm{C}$ $\mathrm{e}-1,6^{\circ} \mathrm{C}$ por oito meses ininterruptos. Nos contrastes $\mathrm{X}_{2}$ e $\mathrm{X}_{3}$ não houve efeito significativo. Temperaturas mais baixas causam inibição de enzimas, dentre elas a ACC oxidase tem sua atividade reduzida (ASIF et al., 2009), a qual é a precursora imediata do etileno.

Para maçãs cultivar Fuji, temperaturas de $-0,8^{\circ} \mathrm{C}$, ou inferior, quando usadas no início do armazenamento, provocam maior degenerescência 
causada por baixa temperatura e tendem a causar mais podridões. No entanto, a temperatura de $-0,8^{\circ} \mathrm{C}$ pode ser usada no final do armazenamento, assim mantendo melhor a qualidade da maçã 'Fuji'.

\section{Referências}

ASIF, M. H.; PATHAK, N.; SOLOMOS, T.; TRIVEDI, P. K. Effect of low oxygen, temperature and 1-methylcyclopropene on the expression of genes regulating ethylene biosynthesis and perception during ripening in apple, South African Journal of Botany, Peitermaritzburg, v. 75, n. 1, p. 137-144, 2009.

BRACKMANN, A.; ANESE, R. O.; PINTO, J. A. V.; STEFFENS, C. A.; GUARIENTI, A. J. W. Temperatura, umidade relativa e atraso na instalação da atmosfera controlada no armazenamento de maçã 'Fuji'. Ciência Rural, Santa Maria, v. 39, n. 8, p.2367-2372, 2009.

BRACKMANN, A.; BORTOLUZ, L.; BORTOLUZZI, G. Frigoconservação de maçãs 'Fuji' em duas temperaturas e em atmosfera controlada. Revista Brasileira de Agrociência, Pelotas, v. 4, n. 1, p. 26-30, 1998.

BRACKMANN, A.; MELLO, A. M.; FREITAS, S. T.; VIZZOTTO, M.; STEFFENS, C. A. Armazenamento de maçãs 'Royal Gala' sob diferentes temperaturas e pressões parciais de oxigênio e gás carbônico. Revista Brasileira de Fruticultura, Jaboticabal, v. 23, n. 3, p. 532-536, 2001.

BRACKMANN, A.; STEFFENS, C. A.; HUNSCHE, M. Influência da instalação das condições de atmosfera controlada e concentração de etileno sobre a qualidade da maçã 'Gala'. Revista Brasileira de Armazenamento, Viçosa, v. 25, n. 1, p. 22-27, 2000.

CHITARRA, M. I. F.; CHITARRA, A. B. Pós-colheita de frutas e hortaliças: fisiologia e manuseio. Lavras: UFLA, 2005. v. 1, 783 p.

FLORES-CANTILLANO, F.; GIRARDI, C. L. Maçã pós-colheita: distúrbios fisiológicos. Bento Gonçalves: Empresa Brasileira de Pesquisa Agropecuária, 2004. 109 p.

GRAN, C. D.; BEAUDRY, R. M. Modified atmosphere packaging determination of lower oxygen limits for apple fruit using respiratory quotient and ethanol accumulation. In: INTERNATIONAL CONTROLLED ATMOSPHERE RESEARCH CONFERENCE, 6., 1993, Ithaha. Proceedings... Ithaca: University of Cornell, 1993. v. 2, p. 54-62.

JAMES, H. J.; JOBLING, J. J. Contrasting the structure and morphology of the radial and diffuse flesh browning disorders and $\mathrm{CO}_{2}$ injury of 'Cripps Pink' apples, Postharvest Biology Technology, Amsterdam, v. 53, n. 1/2, p. 36-42, 2009.

LITTLE, C. R.; BARRAND, L. The effect of preharvest, postharvest and storage conditions on some fruit disorders. In: INTERNATIONAL CONTROLLED ATMOSPHERE RESEARCH CONFERENCE, 5., 1989, Washington. Proceedings... Washington: Washington Satate University, 1989. v. 1, p. 185-192.

LYONS, J. M. Chilling injury in plant. Annual Review of Plant Physiology, Rockville, v. 1, n. 24, p. 495-496, 1973.

VOLZ, R. K.; BIASI, W. V.; GRANT, J. A.; MITCHAM, E. J. Prediction of controlled atmosphere-induced flesh browning in 'Fuji' apple. Postharvest Biology Technology, Amsterdam, n. 2, v. 13, p. 97-107, 1998.

WATKINS, C. B.; BURMEISTER, D. M.; ELGAR, H. J.; LIU, F. W. A comparison of two carbon dioxiderelated injuries of apple fruit. In: INTERNATIONAL CONTROLLED ATMOSPHERE RESEARCH CONFERENCE, 7., 1997, Davis. Proceedings.... Davis: University of California, 1997. v. 2, p. 119-124. 
